\title{
Influence of Underground Tunnel Excavation on Upper-level Existing Pipelines
}

\author{
Xingfa Feng, ${ }^{1}$ Xian Yang $\left(\mathbb{D},{ }^{2}\right.$ Yongsuo $\mathrm{Li}^{3}$, and Xingyu Ding ${ }^{2}$ \\ ${ }^{1}$ CCTEG, Chongqing Eenineering (GROUP) Co., Ltd, Chongqing 40000, China \\ ${ }^{2}$ College of Civil Engineering, Hunan City University, Yiyang, Huhan 4130003, China \\ ${ }^{3}$ School of Municipal and Geomatics Engineering, Hunan City University, Yiyang, Huhan 4130003, China
}

Correspondence should be addressed to Xian Yang; yangxjj@163.com

Received 10 December 2021; Accepted 19 January 2022; Published 28 February 2022

Academic Editor: Yu Liang

Copyright ( $\odot 2022$ Xingfa Feng et al. This is an open access article distributed under the Creative Commons Attribution License, which permits unrestricted use, distribution, and reproduction in any medium, provided the original work is properly cited.

Winkler elastic foundation beam theory is often used to observe the influence of underground engineering construction on pipelines. Excavation under existing pipelines disturbs the lower strata to varying extent, which creates significant differences in the subgrade coefficients. Ignoring these differences can severely impact the accuracy of calculation results. A theoretical model of the effects of underground excavation on upper-level existing pipelines was developed in this study based on Winkler elastic foundation beam theory and considering the difference of subgrade coefficients under the existing pipeline. Methods for determining the subgrade coefficient under the influence of construction disturbance and other relevant parameters are proposed. The theoretical model can be used to calculate the settlement of an existing pipeline under the influence of underground excavation. The calculated settlement was compared with settlement measurements to find that the subgrade coefficient of the excavation section is the most important parameter in the calculation process. The suitable value range of the excavation subgrade coefficient is relatively large, as it has a relatively minor influence on the calculation result. When the value of subgrade coefficient of each section is appropriate, the calculated settlement curve is in close accordance with the measured settlement curve.

\section{Introduction}

The gradual development and utilization of urban underground spaces have produced a number of underground excavation projects affecting existing pipelines [1-3]. In the process of an underground engineering project, disturbance to the stratum inevitably deforms the adjacent underground pipeline. When the deformation exceeds the allowable deformation of the existing pipeline and its joints, destruction of the existing pipeline may result in even serious secondary disasters. It is difficult to directly monitor the deformation of existing pipelines due to the distribution of points above ground throughout a ground excavation project. The points instead can only be monitored indirectly [4], which does not readily allow for effective accident prediction or prevention. There is an urgent demand for a straightforward and easily applied method to evaluate the safety of existing pipelines and classify construction risks. Such evaluations would facilitate the proper selection of preconstruction reinforcement or relocation treatment for existing pipelines to minimize the failure risk of existing pipelines, save costs, and shorten the construction period.

Previous studies regarding the impact of tunnel construction on existing pipelines have mainly centered on numerical simulations and theoretical analyses. Theoretical analysis methods are mainly based on the Winkler elastic foundation beam theory $[5,6]$, two-parameter Pasternak elastic foundation beam theory [7, 8], or energy method [9] to solve parameters such as the deformation, bending moment, and shear force of an existing pipeline as affected by tunnel construction and to select corresponding standards to judge its safety. Unlike the two-parameter elastic foundation beam theory, the Winkler elastic foundation beam theory does not reflect the continuity of foundation deformation. However, a method based on the Winkler elastic foundation beam is simpler, includes more 
accumulated experiences in parameter values, and is most widely used in engineering. The two-parameter elastic foundation beam is more comprehensive in theory but includes less experience in the parameter value selection process; whether the parameter value is appropriate is directly related to the accuracy of calculation results. The Winkler elastic foundation beam theory was utilized in the present study to develop a calculation model of the influence of excavation on the upper-level pipeline.

The stratum under an existing upper-level pipeline is disturbed as an excavation project passes under it. The disturbance is most intense above the excavation section though there is also disturbance in a certain area near the excavation area. The mechanical properties of the soils in these two areas change significantly at this point compared with the original stratum, so there is also a substantial difference in the subgrade coefficient. Previous theoretical calculations have rarely considered the differences in subgrade coefficient in various areas under the existing pipeline, though ignoring such differences drives down the accuracy of calculation results and subsequent pipeline safety assessments.

Based on Winkler elastic foundation beam theory and considering the different subgrade coefficients in each area under the existing pipeline, a theoretical calculation model of the influence of concealed excavation construction on upper existing pipelines was established in this study. Important parameters in the model were acquired, and the influence of different subgrade coefficient values on the predicted deformation of the existing pipeline was observed. A case analysis was conducted to test the proposed method. This work may provide an important reference for the safety assessment of existing pipelines in similar projects.

\section{Theoretical Calculation Model}

Generally, underground pipelines are laid along a roadway. Most underground tunnels cross the road vertically and also intersect with the existing pipelines vertically. The impact of the underground excavation project intersecting with the existing pipeline vertically is under investigation here (Figure 1). Flexible pipes are allowed to rotate after loading, while rigid pipes are not allowed to rotate after loading. The pipe considered in this paper allows rotation angle, so it is suitable for the calculation of flexible pipe.

It is also assumed here that the excavation channel is rectangular and that the foundation is homogeneous. The existing pipeline is regarded as an elastic foundation beam on a Winkle foundation. It is assumed that the settlement of any point in the foundation is only proportional to the pressure on the unit area of the point, regardless of the pressure at other points. There is a relatively long longitudinal extension of the buried pipeline, which is assumed to be an infinite beam. During the underground excavation project, the stress area of the existing pipeline at the upper level is divided into five sections. As shown in Figure 2, the $\mathrm{CD}$ section is the excavation area, $\mathrm{BC}$ and $\mathrm{DE}$ sections are soil-loosening sections caused by excavation, and $\mathrm{AB}$ and $\mathrm{EF}$ sections are areas not affected by excavation. Construction disturbance creates different subgrade coefficients for each

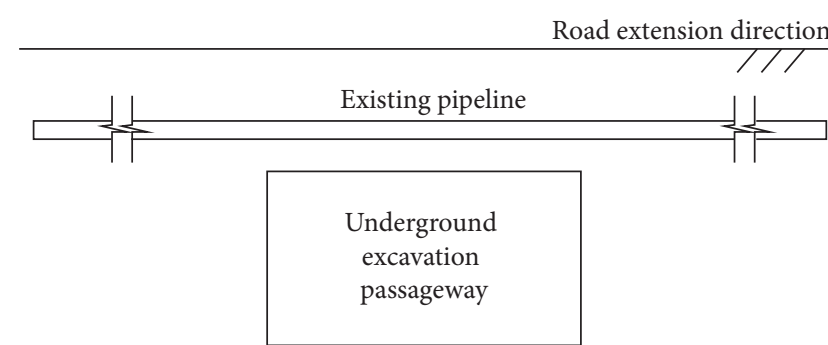

FIgURE 1: Locations of the underground excavation project and existing pipeline.

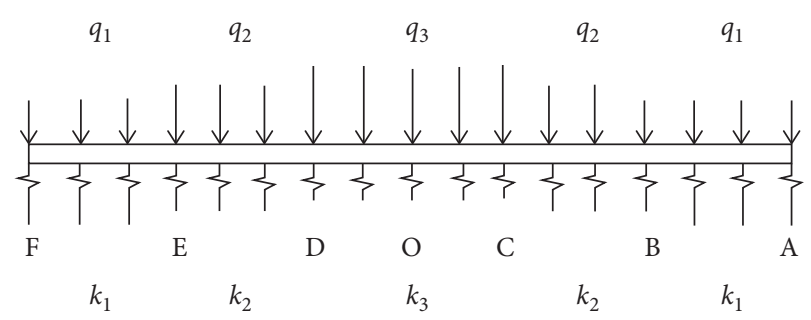

FIGURE 2: Stress diagram of the existing pipe under influence of excavation.

section. It is assumed that the subgrade coefficient of the $A B$ and EF section is $k_{1}$, that of the $\mathrm{BC}$ and DE section is $k_{2}$, and that of the CD section is $k_{3}$.

The maximum load of the buried pipeline mainly originates in the gravity of the soil above it. The Terzaghi loose Earth pressure calculation model is generally used to determine the vertical Earth pressure on a buried pipeline [10]. In the Terzaghi model, the dislocation of soil particles produces stress transfer, which makes the surrounding soil restrict the downward moving soil so that the vertical Earth pressure borne by the underground structure is less than the gravity of the soil column. As shown in Figure 2, if other external loads on the upper part of the existing pipeline are not considered, the uniformly distributed load $q_{1}$ of sections $\mathrm{AB}$ and $\mathrm{EF}$ of the existing pipe jacking is not affected by excavation and can be calculated using the Terzaghi model. The soil above the excavation section and the excavation-affected section is impacted by construction disturbance. The mechanical properties of the soil and the holding capacity of the downward part are reduced, which increases the Earth pressure borne by the underground pipeline. It is assumed that the Earth pressure borne by the pipeline above the excavation section CD is $q_{3}$ and that of the excavation-affected sections $\mathrm{BC}$ and $\mathrm{DE}$ is $q_{2}$.

As shown in Figure 2, the deflection differential equation of each section can be obtained as follows:

$$
\begin{aligned}
& A B: E I \frac{d^{4} \omega_{1}}{d x^{4}}+k_{1} b \omega_{1}-q_{1}=0, \\
& B C: E I \frac{d^{4} \omega_{2}}{d x^{4}}+k_{2} b \omega_{2}-q_{2}=0, \\
& C O: E I \frac{d^{4} \omega_{3}}{d x^{4}}+k_{3} b \omega_{3}-q_{3}=0,
\end{aligned}
$$


where $E I$ is the bending stiffness of the existing pipeline, $\mathrm{N} \cdot \mathrm{m}^{2} ; \omega_{i}$ is the deflection of each section of the existing pipeline, $m, i=1,2,3 ; x$ is the distance between each point in the right half of the existing pipeline and point $\mathrm{O}, m ; k_{i}$ is the subgrade coefficient of each section under the existing pipeline, $\mathrm{N} / \mathrm{m}^{3}, i=1,2,3 ; q_{i}$ is the Earth pressure borne by each section of the existing pipeline, $\mathrm{Pa}, i=1,2,3$; and $b$ is the calculated width of the foundation reaction, $m$.

The characteristic value of flexibility is determined by the calculated width of the foundation reaction.

$$
\lambda_{i}=\sqrt[4]{\frac{k_{i} b}{4 E I}}
$$

where $i=1,2,3$.

The general solution for each section of the deflection differential equation and the first, second, and third derivative of each section can be obtained as follows:

$$
\left\{\begin{array}{l}
\omega_{i}=e^{\lambda_{i} x}\left(A_{i} \cos \lambda_{i} x+B_{i} \sin \lambda_{i} x\right)+e^{-\lambda_{i} x}\left(C_{i} \cos \lambda_{i} x+D_{i} \sin \lambda_{i} x\right)+\frac{q_{i}}{k_{i}}, \\
\omega_{i}^{\prime}=\lambda_{i} e^{\lambda_{i} x}\left[\left(B_{i}-A_{i}\right) \sin \lambda_{i} x+\left(B_{i}+A_{i}\right) \cos \lambda_{i} x\right]+\lambda_{i} e^{-\lambda_{i} x}\left[\left(D_{i}-C_{i}\right) \cos \lambda_{i} x-\left(D_{i}+C_{i}\right) \sin \lambda_{i} x\right], \\
\omega_{i}^{\prime \prime}=2 \lambda_{i}^{2} e^{\lambda_{i} x}\left(B_{i} \cos \lambda_{i} x-A_{i} \sin \lambda_{i} x\right)+2 \lambda_{i}^{2} e^{-\lambda_{i} x}\left(C_{i} \sin \lambda_{i} x-D_{i} \cos \lambda_{i} x\right), \\
\omega_{i}^{\prime \prime}=2 \lambda_{i}^{3} e^{\lambda_{i} x}\left[\left(B_{i}-A_{i}\right) \cos \lambda_{i} x-\left(B_{i}+A_{i}\right) \sin \lambda_{i} x\right]+2 \lambda_{i}^{3} e^{-\lambda_{i} x}\left[\left(D_{i}-C_{i}\right) \sin \lambda_{i} x+\left(D_{i}+C_{i}\right) \cos \lambda_{i} x\right],
\end{array}\right.
$$

where $A_{i}, B_{i}, C_{i}, D_{i}(i=1,2,3)$ are undetermined coefficients.

If the deflection of the beam is known, the rotation angle, bending moment, and shear force of any section of the beam can be obtained according to the knowledge of Material Mechanics.

$$
\left\{\begin{array}{l}
\theta=\omega^{\prime} \\
M=-E I \omega^{\prime \prime}, \\
Q=-E I \omega^{\prime \prime \prime}
\end{array}\right.
$$

where $\theta$ denotes the corners of existing pipelines; $M$ is the bending moment of the existing pipeline, $\mathrm{N} \bullet \mathrm{m}$; and $Q$ is the shear force of the existing pipeline, $N$.

In an actual construction project, the pipeline is quite long. Due to the constraints of the soil around the pipeline on the existing pipeline, the excavation under the pipeline has a limited range of influence. At the end far away from the excavation range $(x, \infty)$, the boundary condition can be assumed to be fixed support. Therefore, the following boundary conditions and deformation coordination conditions hold.

Point $\mathrm{A}(\mathrm{x}, \infty)$ is the fixed end:

$$
\left\{\begin{array}{l}
\omega_{1}=0 \\
\omega_{1}^{\prime}=0 .
\end{array}\right.
$$

Point $\mathrm{O}$ is the symmetrical point:

$$
\left\{\begin{array}{l}
\omega_{3}^{\prime}=0, \\
\omega_{3}^{\prime \prime}=0 .
\end{array}\right.
$$

According to the coordination among deflection, rotation angle, bending moment, and shear force at the left and right ends of points B and C, the following supplementary conditions hold.

Point B:

$$
\left\{\begin{array}{l}
\omega_{1}=\omega_{2}, \\
\omega_{1}^{\prime}=\omega_{2}^{\prime}, \\
\omega_{1}^{\prime \prime}=\omega_{2}^{\prime \prime}, \\
\omega_{1}^{\prime \prime}=\omega_{2}^{\prime \prime} .
\end{array}\right.
$$

Point C:

$$
\left\{\begin{array}{l}
\omega_{2}=\omega_{3}, \\
\omega_{2}^{\prime}=\omega_{3}^{\prime}, \\
\omega_{2}^{\prime \prime}=\omega_{3}^{\prime \prime}, \\
\omega_{2}^{\prime \prime}=\omega_{3}^{\prime \prime} .
\end{array}\right.
$$

A system of 12 equations and 12 unknowns can be established by substituting formulas (5)-(8) into formula (3). The analytical solutions of the undetermined coefficients $A_{i}, B_{i}, C_{i}$, and $D_{i}$ were obtained here in MATLAB and then substituted into formulas (5)-(8) to obtain the deflection, rotation angle, bending moment, and shear force generated at each point in the existing pipeline $\mathrm{AE}$ during excavation of the $\mathrm{BC}$ section. The safety of the existing pipeline can be evaluated based on the results by selecting appropriate judgment standards.

\section{Determination of Relevant Parameters in Theoretical Calculation}

3.1. Calculation of Vertical Earth Pressure on the Existing Pipeline. In this study, the Terzaghi loose Earth pressure calculation model was selected to calculate the vertical Earth 
pressure $q_{1}$ on the existing pipeline not affected by excavation. The soil above the excavation section and the excavation-affected section is impacted by the construction disturbance. The mechanical properties of the soil and holding capacity of the downward moving part are reduced, thus increasing the Earth pressure on the pipeline. Based on the simplified calculation and partial safety considerations, the holding capacity of the surrounding soil to the downward moving part can be ignored. The Earth column theory can be directly used to calculate the Earth pressure $q_{2}$ and $q_{3}$ on the existing pipe jacking above the excavation section and the excavation-affected section.

\subsection{Determination of the Excavation-Affected Section Length.} The angle between the fracture surface and the tunnel excavation surface can be assumed as $\left(45^{\circ}-\varphi / 2\right)$ in the soilloosening area caused by tunnel excavation [11] (Figure 3). The length of the loose section can be calculated as follows:

$$
a=(H+h) \tan \left(\frac{\pi}{4}-\frac{\varphi}{2}\right)
$$

where $a$ is the length of the excavation-affected section, $m ; H$ is the distance between the top of the excavation area and the existing pipeline, $m$; $h$ is the height of the excavation area, $m$; and $\varphi$ is the internal friction angle of soil, .

3.3. Determination of Foundation Reaction Width. Assuming that the diameter of the existing pipeline is $D$, the calculated width of soil reaction $b$ is as follows [12]:

When $B \leq 1 \mathrm{~m}$,

$$
b=0.9(1.5 \mathrm{~d}+0.5) .
$$

When $b>1 \mathrm{~m}$,

$$
b=0.9(\mathrm{~d}+1)
$$

where $d$ is the outer diameter of the existing pipeline, $m$.

3.4. Determination of the Subgrade Coefficient under Construction Disturbance. The subgrade coefficient is the most important parameter in this theoretical model. There have been few previous studies on the influence of construction disturbance on subgrade coefficients, but there are many research results regarding other soil mechanical properties under construction disturbance. Xu Yongfu [13] pointed out that the soil disturbance caused by shield tunneling decreases the deformation modulus by $30-70 \%$, and that the cohesion and internal friction angle are related to the soil strain rate: when the soil strain rate increases from 0 to $6 \%$, the cohesion is completely lost, and the internal friction angle decreases linearly to $50 \%$ of the original value. Liu Zhe [14] divided tunnel excavation disturbance into three areas according to volumetric strain rate (Figure 4): area A, where the volumetric strain exceeds $3 \%$; area $\mathrm{B}$, where the volumetric strain is $1-3 \%$; and area $C$, where volumetric strain is less than $1 \%$. The change range of deformation modulus in each region was found to be greater than that of cohesion and internal friction angle, while the overall change in

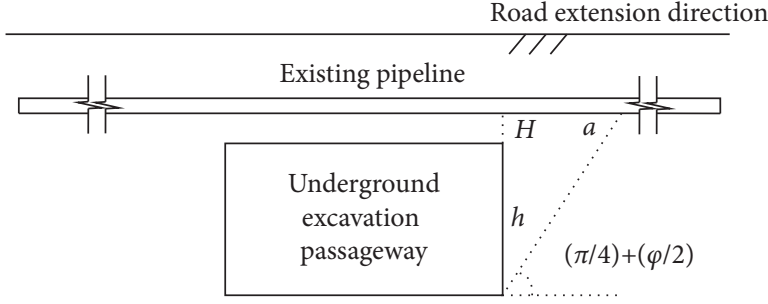

FIgURE 3: Loose soil area length calculation.

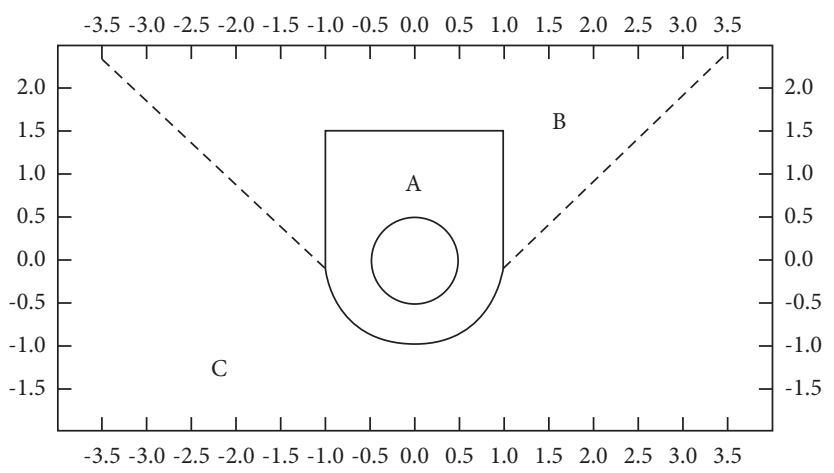

Figure 4: Area disturbed by tunnel excavation.

internal friction angle was minimal. At different points in area $\mathrm{A}$, the deformation modulus decreased by $37-91.7 \%$, the cohesion decreased by $31.4-63.7 \%$, and the internal friction angle decreased by $3.6-12.3 \%$. At different points in area $\mathrm{B}$, the deformation modulus decreased by $8.1-24.1 \%$, the cohesion decreased by $2.5-23.1 \%$, and the internal friction angle decreased by $1.1-2.3 \%$.

For specific projects, the subgrade coefficients of undisturbed soil and disturbed soil should be determined by an in-situ plate load test or indoor consolidation test. If no test data are available, the method proposed by Vesic [15] can be used to determine the subgrade coefficient (formula (8)), where it is not only related to the mechanical properties of the foundation soil itself but also to the action width and stiffness of the beam $[16,17]$. The subgrade coefficient can be also determined by the known deformation modulus and Poisson's ratio. According to the spatial relationship between the existing pipeline and the underground excavation space, and based on the existing literature, the underground excavation disturbance zoning can be defined as shown in Figure 4 . The average deformation modulus and average internal friction angle of the soil in each area can then be estimated. The Poisson's ratio can be obtained by formulas (11)-(12) according to the average internal friction angle, and then, it can be substituted into formula (8) together with the estimated deformation modulus to calculate the subgrade coefficient under the influence of construction disturbance.

$$
k=\frac{0.65 E_{s}^{\prime}}{1-v^{\prime 2}} \sqrt{\frac{E_{s}^{\prime} b^{4}}{\left(1-v^{\prime 2}\right) E I}},
$$


TABle 1: Subgrade coefficient values.

\begin{tabular}{lcccc}
\hline Condition & Subgrade coefficient & $k_{1}\left(\mathrm{kN} / \mathrm{m}^{3}\right)$ & $k_{2}\left(\mathrm{kN} / \mathrm{m}^{3}\right)$ & $k_{3}\left(\mathrm{kN} / \mathrm{m}^{3}\right)$ \\
\hline & Calculated parameter 1 & $1.4 \times 10^{4}$ & $0.3 k_{1}$ & $0.1 k_{1}$ \\
Subgrade coefficient value in excavation section & Calculated parameter 2 & $1.4 \times 10^{4}$ & $0.3 k_{1}$ & $0.05 k_{1}$ \\
& Calculated parameter 3 & $1.4 \times 10^{4}$ & $0.3 k_{1}$ & $0.075 k_{1}$ \\
& Calculated parameter 4 & $1.4 \times 10^{4}$ & $0.3 k_{1}$ & $0.125 k_{1}$ \\
& Calculated parameter 5 & $1.4 \times 10^{4}$ & $0.3 k_{1}$ & $0.15 k_{1}$ \\
\hline & Calculated parameter 1 & $1.4 \times 10^{4}$ & $0.3 k_{1}$ & $0.1 k_{1}$ \\
Subgrade coefficient value in excavation-affected section & Calculated parameter 6 & $1.4 \times 10^{4}$ & $0.6 k_{1}$ & $0.1 k_{1}$ \\
& Calculated parameter 7 & $1.4 \times 10^{4}$ & $0.5 k_{1}$ & $0.1 k_{1}$ \\
& Calculated parameter 8 & $1.4 \times 10^{4}$ & $0.4 k_{1}$ & $0.1 k_{1}$ \\
& Calculated parameter 9 & $1.4 \times 10^{4}$ & $0.2 k_{1}$ & $0.1 k_{1}$ \\
\hline
\end{tabular}

where $E_{s i}$ is the deformation modulus of the soil in each section under the existing pipeline, $\mathrm{Pa} ; v_{i}$ is the Poisson's ratio of the soil in each section under the existing pipeline.

According to the relevant theories of soil mechanics, Poisson's ratio can be calculated according to the lateral pressure coefficient $k_{0 i}$ of each section of soil.

$$
v_{i}=\frac{k_{0 i}}{1+k_{0 i}} \text {. }
$$

The lateral pressure coefficient can be measured with a tri-axial shear meter or lateral pressure meter. When test data are lacking, it can also be determined empirically based on the internal friction angle of each section of soil $\varphi_{i}$.

$$
k_{0 i}=1-\sin \varphi_{i} .
$$

\section{Case Calculation and Analysis}

The case analysis data used in this study were taken from the literature [18]. The Wuhan Zhuodaoquan interchange underground pedestrian passage project is located on the east side of the intersection of Luoyu Road, Zhuodaoquan South Road, and Zhuodaoquan North Road. Zhuodaoquan Park is on the south side of the passage, and Zhuodaoquan Middle School is on the north side. It crosses the Zhuodaoquan interchange and Luoyu Road, connecting the sidewalks on the north and south sides.

The buried depth of the underground pedestrian passage is $3 \mathrm{~m}$, the width is $8 \mathrm{~m}$, and the height is $3.55 \mathrm{~m}$. The overburdened soil of the underpass is mainly silty clay with cohesion of $15 \mathrm{kPa}$, internal friction angle of $12^{\circ}$, gravity of $19.3 \mathrm{kN} / \mathrm{m}^{3}$, and subgrade coefficient of $1.4 \times 10^{4} \mathrm{kN} / \mathrm{m}^{3}$. (This subgrade coefficient was calculated by the method in Section 3.3 according to the deformation modulus given in the literature.) There is a DN100 cast iron pipe above the underpass with an outer diameter of $114 \mathrm{~mm}$ and a buried depth of $1.5 \mathrm{~m}$. The existing pipeline settlement calculated by the proposed method was compared against the field-measured settlement under different subgrade coefficients (Table 1) in the excavation section and excavation-affected section (Figures 5-6).

As shown in the figures above, when the subgrade coefficient of the excavation section is $10 \%$ of the original subgrade coefficient and the subgrade coefficient of the excavation-affected section is $30 \%$ of the original subgrade coefficient, the calculated settlement curve is consistent with the measured settlement curve (calculated value 1 and measured value). The maximum settlement occurs at the midpoint of the concealed excavation section, and the calculated value is slightly greater than the measured value. The widths of both the left and right sides of the settlement curve calculated and measured are about $12 \mathrm{~m}$. There is only a slight difference between the measured and calculated values of each measuring point. The calculated value slightly exceeds the measurement for the area with a large settlement (0-3 $\mathrm{m}$ from the midpoint of the excavation section) but still satisfies the engineering requirements for a safe prediction. With an increase in the distance from the center, the measured curve shows a continuous decreasing trend while the calculated curve shows a sudden change. The reason for this difference is the inherent deficiency of the Winkle elastic foundation beam theory, which does not reflect the continuity of foundation deformation.

The results of calculations show that the subgrade coefficient of the excavation section is the most critical parameter in the calculation, which directly affects the settlement calculation results of the maximum settlement and the area with maximum settlement (the interval $0-3 \mathrm{~m}$ from the midpoint of the excavation section). In this case, when the subgrade coefficient of the excavation section is $25 \%$ less than the applicable value $\left(0.1 \mathrm{k}_{1}\right)$, the calculated maximum settlement value increases by $35 \%$. When the subgrade coefficient of the excavation section is $25 \%$ greater than the applicable value $\left(0.1 \mathrm{k}_{1}\right)$, the calculated maximum settlement value increases by $20 \%$. It can be seen that the value of this parameter has a great impact on the calculation results and is directly related to the accuracy of prediction and evaluation. Therefore, if possible, indoor and in-site tests shall be used to determine the subgrade coefficient of the excavation section.

The subgrade coefficient of the excavation-affected section appears to have negligible impact on the maximum settlement, little impact on the settlement calculation results of the maximum settlement area $(0-3 \mathrm{~m}$ from the midpoint of the concealed excavation section), and a relatively large impact on the second-largest settlement area (3-9 m from the midpoint of the concealed excavation section). If the subgrade coefficient value in the excavation section is accurate and its value in the excavation-affected section (relative to $0.3 \mathrm{k}_{1}$ ) increases or decreases by $30 \%$, the difference in the calculated maximum settlement and maximum settlement area values is relatively small, and all values are conservative. The difference among calculated values in 


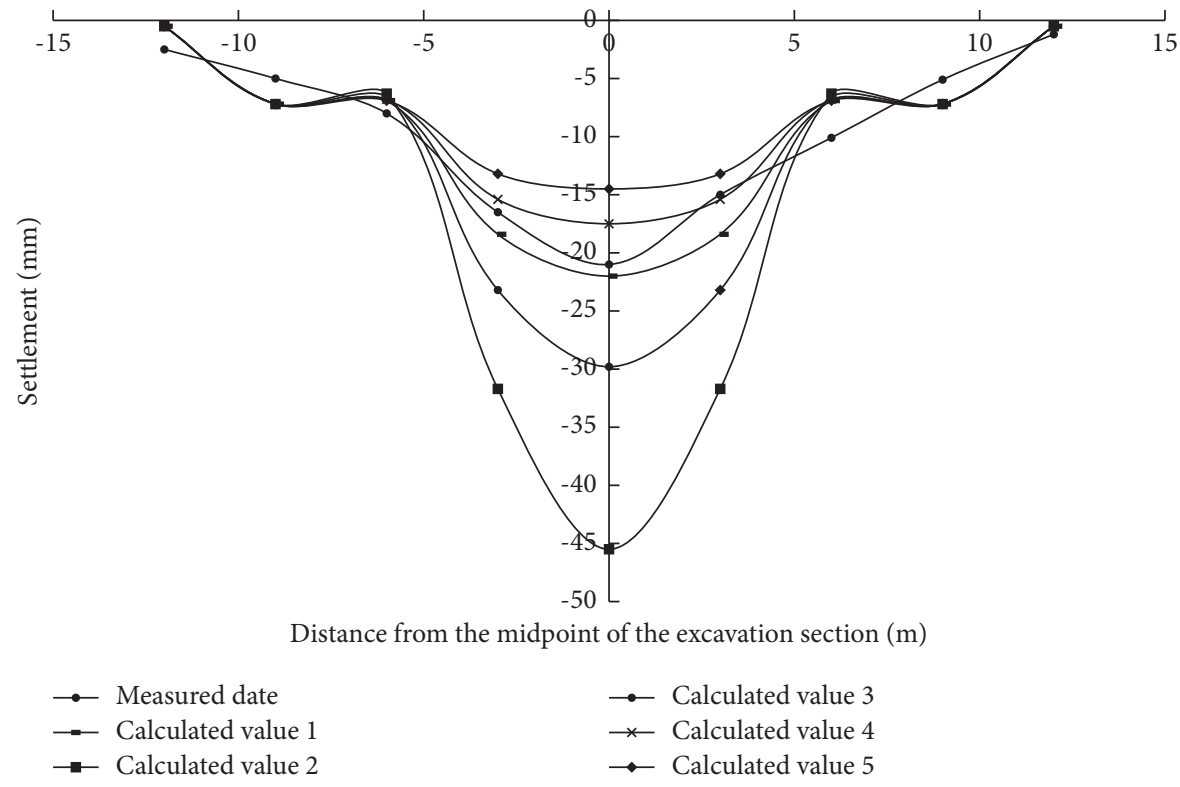

FIGURE 5: Comparison of measured and calculated settlement different subgrade coefficient values in excavation section.

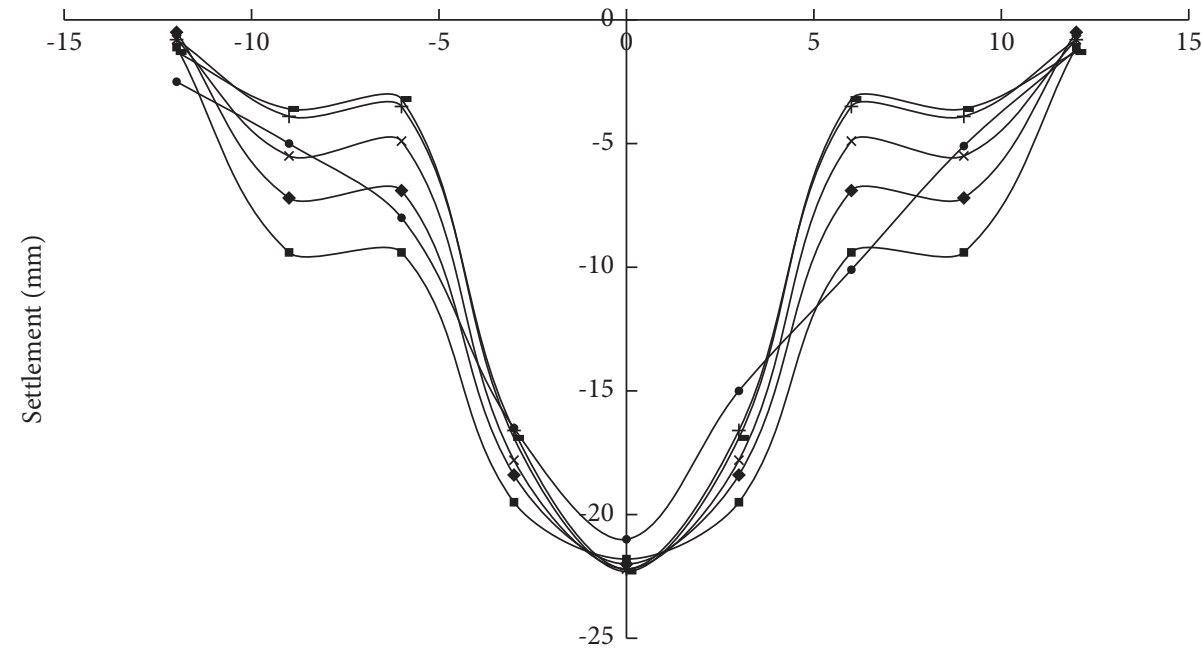

Distance from the midpoint of the excavation section $(\mathrm{m})$

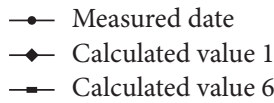

$\leftarrow$ Calculated value 7
$*$ Calculated value 8
$\rightarrow \quad$ Calculated value 9

Figure 6: Comparison of measured and calculated settlement different subgrade coefficient values in excavation-affected section.

the second-largest settlement area is relatively large, but the absolute difference in calculated values is below $2.5 \mathrm{~mm}$. Overall, the appropriate value range of this parameter is relatively large, and the deviation is within $30 \%$, which indicates the relatively little impact on the pipeline settlement value calculation results.

\section{Conclusion}

Based on the Winkler elastic foundation beam theory and considering the difference of the subgrade coefficient in each area under the existing pipeline, a theoretical calculation model for the effects of underground excavation on an upper-level upper existing pipeline was established in this study. The deflection, rotation angle, bending moment, and shear force of each point of the existing pipeline can be calculated using this model, and then, the safety of the existing pipeline can be evaluated by selecting appropriate judgment criteria. Further, model parameters such as the vertical Earth pressure of each section on the existing pipeline, the length of the excavation-affected section, the calculated width of the foundation reaction, and the subgrade coefficient under the influence of construction disturbance were empirically determined. When there is no test 
data for reference, the estimated deformation modulus and Poisson's ratio values can be determined based on the disturbance zoning. The subgrade coefficient under construction disturbance can be calculated according to the method proposed by Vesic.

The proposed method was used to calculate the settlement of an existing pipeline under the influence of excavation, and the results were compared against measured settlement values. When the subgrade coefficient is appropriate, the calculated settlement curve is in close agreement with the measured settlement curve. With an increase in the distance from the center, the measured curve shows a continuous decreasing trend while the calculated curve shows a sudden change. The reason for this difference is the inherent deficiency of the Winkle elastic foundation beam theory, which does not reflect the continuity of foundation deformation.

The foundation bed coefficient of the excavation section is the most important parameter in the calculation process. Its value significantly affects the final calculation results and is directly related to the accuracy of predictions and evaluations. If possible, both indoor and on-site tests should be conducted to determine the subgrade coefficient of the excavation section. The appropriate value range of the subgrade coefficient of the excavation-affected section is relatively large, and the value deviation is within $30 \%$, which indicates a relatively slight impact on the pipeline settlement calculation results.

\section{Data Availability}

All data included in this study are available upon request to the corresponding author.

\section{Conflicts of Interest}

The authors declare that they have no conflicts of interest.

\section{Acknowledgments}

This study was supported by the Natural Science Foundation of Hunan Province (2021JJ30078).

\section{References}

[1] D. Zhang, "Case study on pipeline relocation of Lanzhou Zhongchuan International Airport comprehensive transportation hub project," Water \& Wastewater Engineering, vol. 046, no. 002, pp. 85-89, 2020.

[2] Z. Zhang, M. Zhang, and Q. Zhao, "A simplified analysis for deformation behavior of buried pipelines considering disturbance effects of underground excavation in soft clays," Arabian Journal of Geosciences, vol. 8, no. 10, pp. 7771-7785, 2015.

[3] Y. Xia, N. Jiang, C. Zhou, and X. Luo, "Safety assessment of upper water pipeline under the blasting vibration induced by Subway tunnel excavation," Engineering Failure Analysis, vol. 104, no. 06, pp. 626-642, 2019.

[4] S. Hu and Y. Li, "Study of settlement control and monitoring plan for shallow excavation tunneling under-crossing existing pipeline," Municipal Engineering Technology, vol. 30, no. 05, pp. 81-85, 2012.

[5] P. B. Attewall, J. Yeates, and A. R. Selby, Soil Movements Induced by Tunneling and Their Effects on Pipelines and structures, Blackie and Son Ltd, London, 1986.

[6] B. Gao, "Theory analysis of rigid connection pipeline deformation affected by tunneling construction of metro tunnel," Journal of Disaster Prevention and Mitigation Engineering, vol. 37, no. 02, pp. 116-121, 2017.

[7] Y. Shang, Study on the Influence Mechanism of Environment and Monitoring \& Early-Warning of the shield, Shanghai Jiao Tong University, Shanghai, 2018.

[8] W. Gang, B. Wang, and X. Xu, "Vertical displacement of underground pipeline caused by shield tunnel crossing in Pasternak foundation," Science Technology and Engineering, vol. 17, no. 33, pp. 158-165, 2017.

[9] W. Gang, C. C. Hong, and X. Xu, "Calculation of pipeline settlement induced by double-O-tube shield tunneling based on energy method," Chinese Journal of Underground Space and Engineering, vol. 115, no. 04, pp. 155-160, 2019.

[10] K. T. Terzaghi, Theoretical Soil Mechanics, INC, 1943.

[11] H. Wang, Research on Mechanism of Pipe Roof Reinforcement and Tunnel Face Stability, Dalian University of Technology, Dalian, 2009.

[12] Ministry of Construction of the People's Republic of China, Code for Design of Building Foundation (GB50007-2011), China Architecture \& Building Press, Beijing, 2011.

[13] Y. Xu and J. Sun, "The influence of shield tunneling on surrounding soil," Tunnel and Rail Transit, vol. 12, no. 2, pp. 9-13, 1999.

[14] Z. Liu, Study on Disturbance of Subway Tunnel Construction and its Effect on the Bridge Pier and Line of the Adjacent HighSpeed railway, Beijing Jiaotong University, Beijing, 2018.

[15] A. B. Vesic, "Beams on Elastic Sub-grade and the Winkler's hypothesis," in Proceedings of the 5th international conference of soil mechanics, pp. 845-850, Paris, France, 1961.

[16] K. Terzaghi, "Evalution of conefficients of subgrade reaction," Géotechnique, vol. 5, no. 4, pp. 297-326, 1955.

[17] M. A. Biot, "Bending of an infinite beam on an elastic foundation," Journal of Applied Physics, vol. 12, no. 2, pp. 155-164, 1937.

[18] Y. Zhang, Study on the Influence of Shallow Excavation on Municipal Underground pipeline, Wuhan University of Technology, Wuhan, 2015. 